\title{
Selection of olive varieties for tolerance to iron chlorosis
}

\author{
Esteban Alcántara $^{1 *}$, Antonio Manuel Cordeiro², Diego Barranco ${ }^{1}$ \\ 1 Departamento de Agronomía, Escuela Técnica Superior de Ingenieros Agrónomos y de Montes, Universidad de Córdoba, Apdo. 3048-14080, \\ Córdoba, Spain \\ 2 Departamento de Olivicultura, Estaçao National de Fruticultura Vieira Natividae, Apdo 145-7350, Elvas, Portugal
}

Received December 5, $2002 \cdot$ Accepted April 3, 2003

\begin{abstract}
Summary
Under certain conditions, olive trees grown on calcareous soils suffer from iron chlorosis. In the present study several olive varieties and scion-rootstock combinations were evaluated for their tolerance to iron chlorosis. Plants were grown over several months in pots with a calcareous soil, under two fertilization treatments. These consisted of periodic applications of nutrient solutions containing either, $30 \mu \mathrm{mol} / \mathrm{L}$ FeEDDHA or not Fe. Tolerance was assessed by the chlorosis and growth parameters of plants grown without Fe, compared to those plants grown with Fe. Results show that there are differences in tolerance among olive varieties and that tolerance is mainly determined by the genotype of the rootstock. These results open the way to use tolerant varieties for those conditions where iron chlorosis could become a problem.
\end{abstract}

Key words: iron-chlorosis - olive varieties - scion-rootstock

\section{Introduction}

Iron chlorosis is a nutrient disorder caused by iron (Fe) deficiency. The typical symptoms consist of an interveinal yellowing or chlorosis of young leaves. Iron is an essential micronutrient that linked to proteins participates in different metabolic process such as chlorophyll synthesis or electron transport through the respiratory and the photosynthetic chains (see Chaney 1984 and Korcak 1987 for general reviews).

Plants growing on calcareous soils are faced with characteristic problems in relation with Fe acquisition. The total Fe content in these soils is high but the available fraction for the plants is insufficient. This is caused by the very low solubility of iron oxides at the alkaline $\mathrm{pH}$ conditions that are buffered by the presence of bicarbonate in these soils (Lindsay and

*E-mail corresponding author: ag1alvae@uco.es
Schwab 1982). The incidence of iron chlorosis depends on numerous factors, such as the properties of the iron oxides and carbonates present in the soil, high water or compacted soil conditions, high or low temperatures, and plant genotype (Perret and Koblet 1984, Inskeep and Bloom 1986, Loeppert 1986, Wei et al. 1994). Tolerant plants can adapt to these conditions by developing different strategies that allow them to solubilise and absorb the required Fe (Römheld and Marschner 1986, Guerinot and Yi 1994).

One of the best alternatives to prevent iron chlorosis problems is the use of tolerant plant species or genotypes. Differences in tolerance have been found in many herbaceous and woody species (Hamzé et al. 1986, Kolesch et al. 1987, Zaiter et al. 1988, Chaney et al. 1992, Tagliavini et al. 1993, Cianzio 1995, Socias i Company et al. 1995). With fruit trees it is common to use the commercial varieties grafted on tolerant rootstocks, as the plant tolerance is mainly determined by the 
rootstock genotype (Byrne et al. 1989, Almaliotis et al. 1995 Socias i Company et al. 1995).

For selecting tolerant plant material different methods have been used. The most general are field experiments, growth in pots with calcareous soil and hydroponic culture with high bicarbonate and low Fe concentrations. Field experiments have been successfully used for herbaceous species such as soybean (Cianzio et al. 1979) or chickpea (Singh et al. 1986) and for woody species such as grape-vine (Kolesch et al. 1987) or peach rootstocks (Byrne 1988). In pots and hydroponics culture the plants are grown under controlled and uniform conditions, and so avoid the variability of soil and environmental conditions characteristic of field experiments, and in general the experimental period required is shorter than in the field. Pot experiments have been used, for example, with soybean (Fairbanks et al. 1987), subclover (Wei et al. 1994) and pear rootstocks (Tagliavini et al. 1993). Examples of the hydroponic culture method can be found for soybean (Coulombe et al. 1984), chickpea (Chaney et al. 1992) and prunus rootstocks (Romera et al. 1991, Shi and Byrne 1995).

There is very little information about genotypic differences in tolerance to iron chlorosis regarding olive trees. Therefore, the objective of this study was to evaluate the tolerance of different olive varieties and scion-rootstock combinations, by growing plants in pots with a calcareous soil.

\section{Materials and Methods}

Three independent experiments were carried out, the first to compare varieties and the remaining to compare scion-rootstock combinations. Young olive (Olea europaea L.) plants were provided by the «Banco Mundial de Variedades de Olivo de Córdoba», produced by vegetative propagation from softwood cuttings. For the experiments with scion-rootstock combinations, plants were grafted by chip budding.

Table 1. Final SPAD and shoot dry weight of eight olive varieties grown in pots with calcareous soil fertilized with nutrient solution with Fe (+ Fe) or without $\mathrm{Fe}(-\mathrm{Fe})$. Values are mean $\pm \mathrm{SE}(\mathrm{n}=12)$. The relative values in the $(-\mathrm{Fe})$ treatment with respect to the $(+\mathrm{Fe})$ treatment, expressed as percentage, are also included.

\begin{tabular}{|c|c|c|c|c|c|c|}
\hline \multirow[t]{2}{*}{ Variety } & \multicolumn{3}{|c|}{ Final SPAD } & \multicolumn{3}{|c|}{ Shoot dry weight (g/plant) } \\
\hline & $+\mathrm{Fe}$ & $-\mathrm{Fe}$ & $\begin{array}{c}-\mathrm{Fe} /+\mathrm{Fe} \\
(\%)\end{array}$ & $+\mathrm{Fe}$ & $-\mathrm{Fe}$ & $\begin{array}{c}-\mathrm{Fe} /+\mathrm{Fe} \\
(\%)\end{array}$ \\
\hline Arbequina & $51.2 \pm 1.1$ & $11.7 \pm 0.8$ & 23 & $12.8 \pm 1.6$ & $0.5 \pm 0.1$ & 4 \\
\hline Cornezuelo de Jaén & $57.8 \pm 0.8$ & $19.5 \pm 3.7$ & 34 & $12.2 \pm 2.3$ & $4.3 \pm 0.9$ & 35 \\
\hline Galega & $52.3 \pm 1.1$ & $16.6 \pm 1.8$ & 31 & $6.2 \pm 1.5$ & $0.3 \pm 0.1$ & 5 \\
\hline Leccino & $48.3 \pm 2.9$ & $3.2 \pm 1.3$ & 7 & $10.8 \pm 4.0$ & $0.6 \pm 0.3$ & 6 \\
\hline Lechín de Sevilla & $50.1 \pm 1.5$ & $12.8 \pm 3.4$ & 26 & $19.0 \pm 1.8$ & $0.9 \pm 0.2$ & 5 \\
\hline Manzanilla de Sevilla & $63.1 \pm 0.4$ & $35.1 \pm 1.6$ & 56 & $15.0 \pm 2.8$ & $7.5 \pm 0.5$ & 50 \\
\hline Nevadillo Negro & $58.5 \pm 0.4$ & $46.8 \pm 3.7$ & 80 & $15.7 \pm 2.7$ & $12.7 \pm 0.6$ & 81 \\
\hline Pajarero & $62.3 \pm 1.1$ & $37.7 \pm 3.0$ & 61 & $18.4 \pm 2.9$ & $12.0 \pm 1.6$ & 65 \\
\hline
\end{tabular}

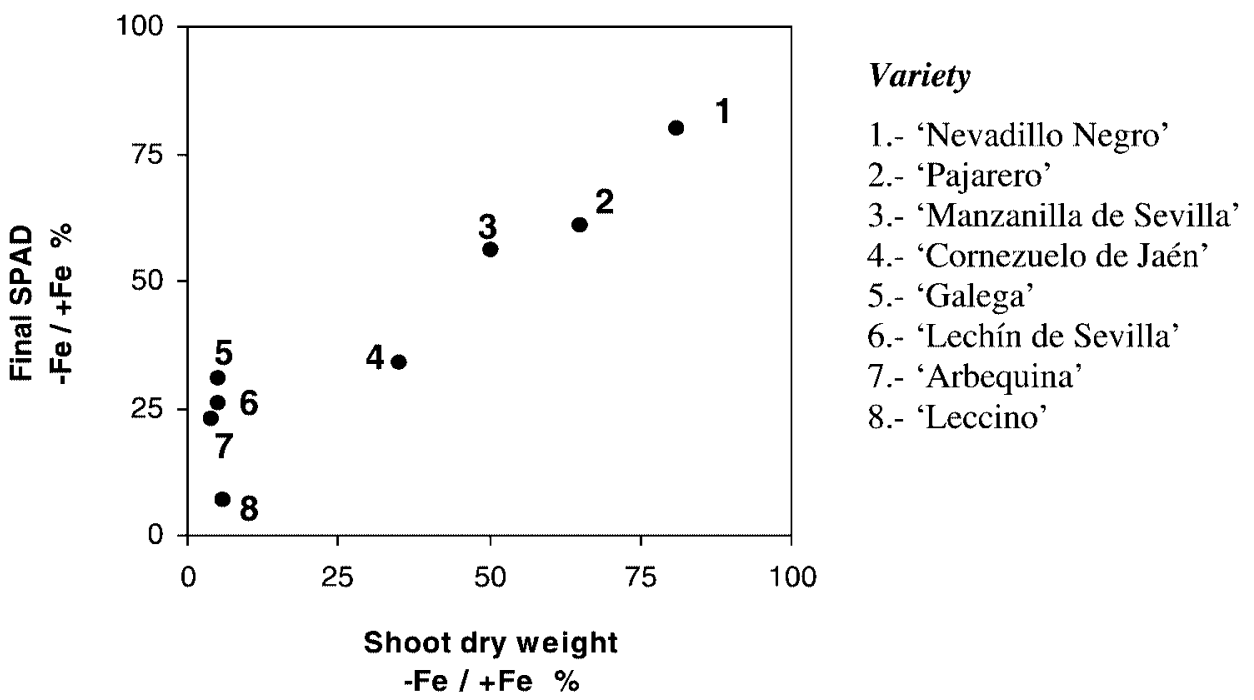

Figure 1. Relationship between the relative final SPAD and shoot dry weight values from Table 1. 

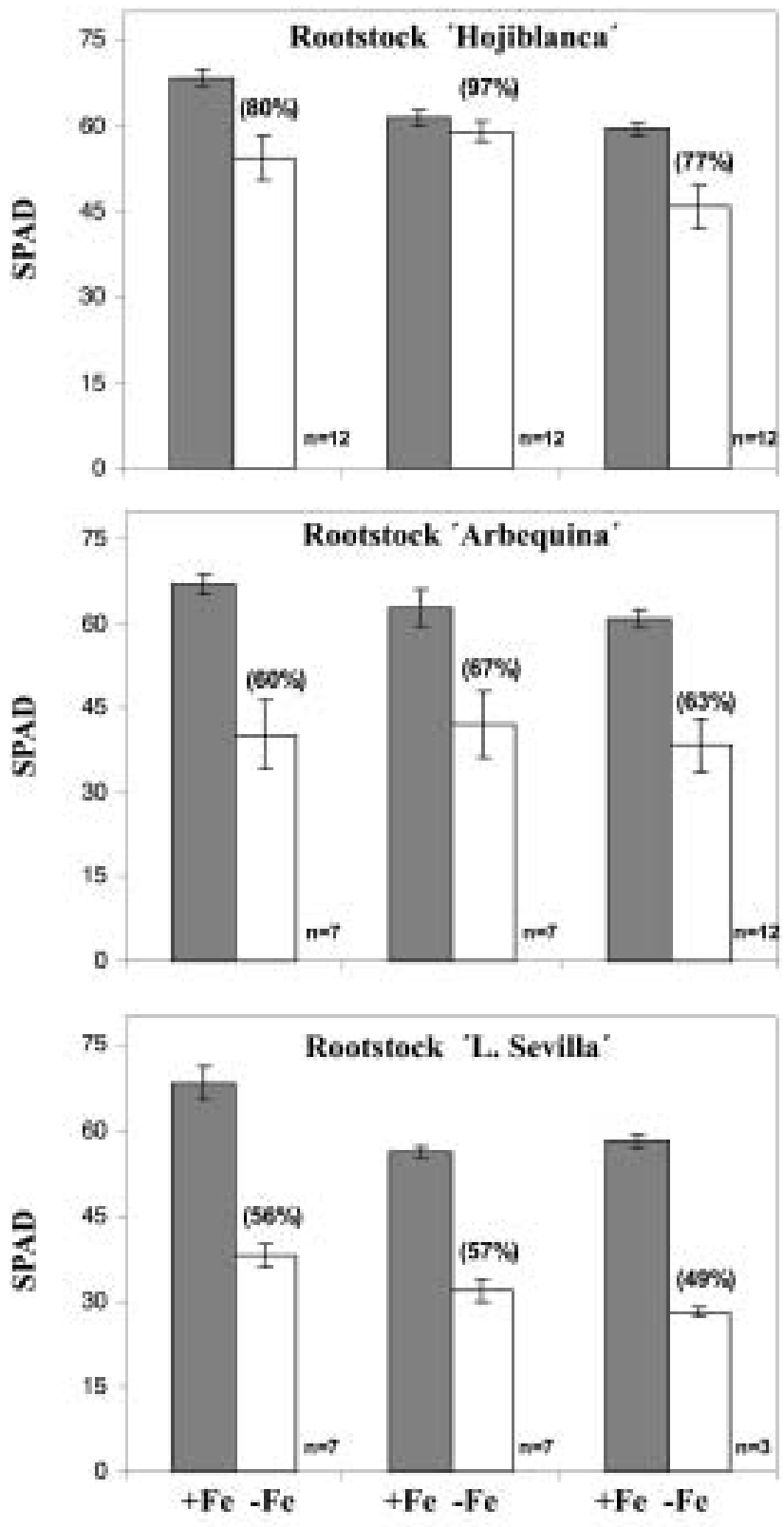

'Hojiblanca' 'L. Sevilla' 'Arbequina'

\section{Scion variety}

Figure 2. Final SPAD of the nine scion-rootstock combinations obtained by combining three olive varieties, "Hojiblanca", ‘Arbequina and 'Lechín de Sevilla, used either as scion or rootstock. Plants were grown in pots with calcareous soil fertilized with nutrient solution with $\mathrm{Fe}(+\mathrm{Fe})$ or without $\mathrm{Fe}(-\mathrm{Fe})$. Values are mean $\pm \mathrm{SE}$ (the number of replications for each combination is indicated in the graphs). The relative values, as percentages, are given in brackets.

In all experiments plants were grown in a greenhouse where the minimum temperature in winter did not descend bellow $10^{\circ} \mathrm{C}$ and the maximum in summer did not exceed $32^{\circ} \mathrm{C}$. Each plant grew individually in
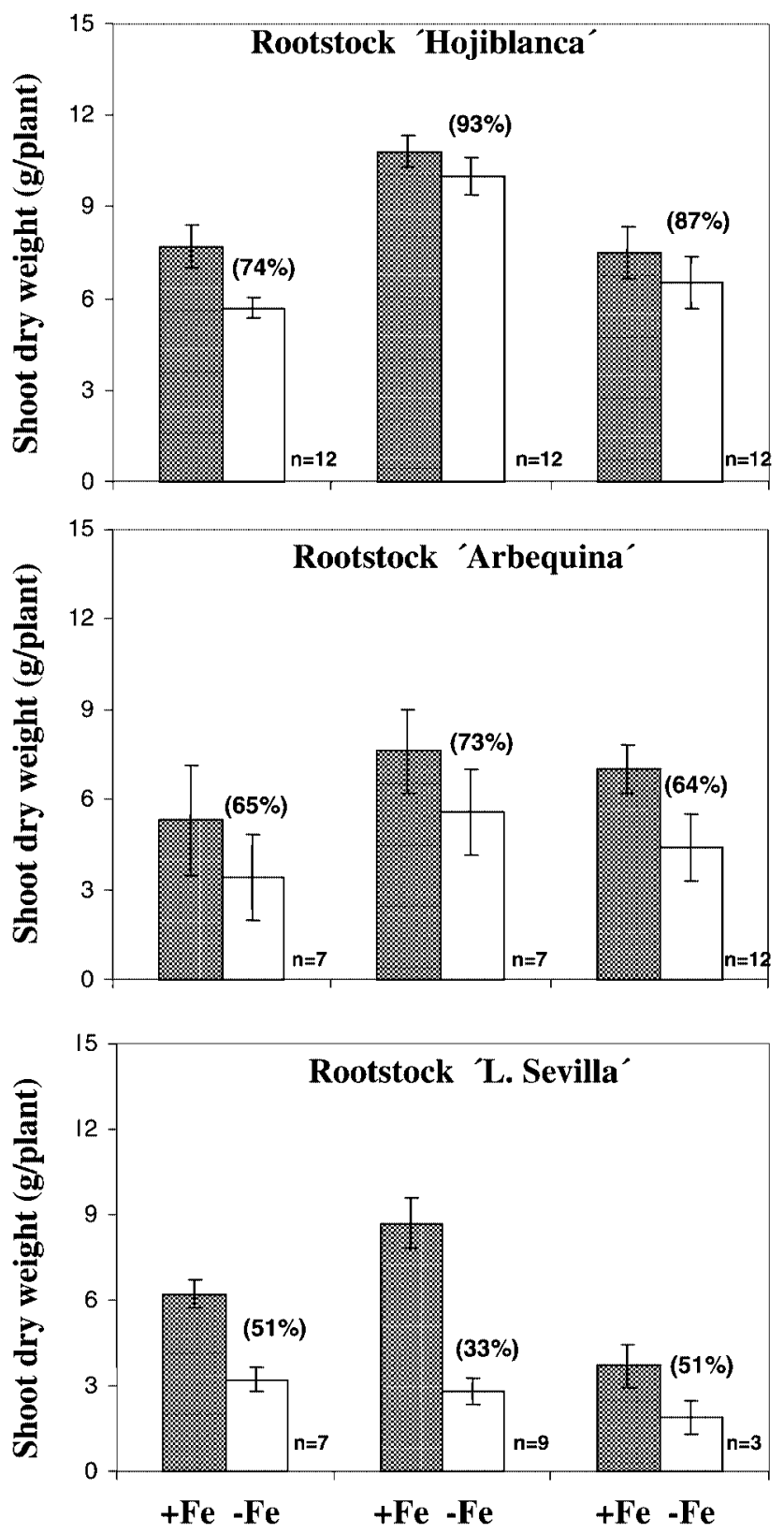

\section{'Hojiblanca' 'L. Sevilla' 'Arbequina'}

\section{Scion variety}

Figure 3. Shoot dry weight of the same nine scion-rootstock combinations presented in Figure 2. Other indications are as in Figure 2.

a $3 \mathrm{~L}$ pot containing a calcareous soil mixed with sand in a $3: 1(\mathrm{v}: \mathrm{v})$ proportion. Two fertilization treatments, $(+\mathrm{Fe})$ and $(-\mathrm{Fe})$, were applied. The number of plant replications depended on plant availability and was 12 for the experiments with non-grafted plants and 3 to 12 for the experiments with grafted plants.

Fertilization treatments consisted of the weekly irrigation with $200 \mathrm{~mL}$ per plant of the corresponding nutrient solution. The composi- 
tion of the nutrient solution was (in $\mathrm{mmol} / \mathrm{L}$ ): $2, \mathrm{Ca}\left(\mathrm{NO}_{3}\right)_{2} ; 0.75, \mathrm{~K}_{2} \mathrm{SO}_{4}$; $0.65, \mathrm{MgSO}_{4} ; 0.5, \mathrm{KH}_{2} \mathrm{PO}_{4}$; and (in $\mu \mathrm{mol} / \mathrm{L}$ ): $50, \mathrm{KCl} ; 10, \mathrm{H}_{3} \mathrm{BO}_{3} ; 1$, $\mathrm{MnSO}_{4} ; 0.5, \mathrm{CuSO}_{4} ; 0.5, \mathrm{ZnSO}_{4} ; 0.05,\left(\mathrm{NH}_{4}\right)_{6} \mathrm{Mo}_{7} \mathrm{O}_{24}$. It also contained $30 \mu \mathrm{mol} / \mathrm{L}$ FeEDDHA for the $(+\mathrm{Fe})$ treatment and no Fe for the $(-\mathrm{Fe})$ treatment. The first experiment started at the beginning of November and lasted for 203 days. The second experiment started at the beginning of May and lasted for 92 days. The third experiment started in the middle of June and lasted for 58 days. Though the first experiment was longer it should be considered that growth of plants during the first half of the period was negligible, so the effective period of growth was around 100 days.

During the experimental periods chlorosis and growth parameters were periodically determined. Chlorosis was measured in young leaves by means of a portable chlorophyll-meter (SPAD-502, Minolta) that gives SPAD values related to the chlorophyll content, so that low SPAD values are an indication of low chlorophyll content. Growth was measured by the increase in length of shoots developed. At the end of the experiments the dry weight of this shoot growth was obtained. For simplicity, only final data are presented as they were representative of the entire experimental period.

\section{Results}

In the first experiment, eight varieties were compared and clear differences in tolerance were observed. The final SPAD values and the shoot dry weight are presented in Table 1. In the $(+\mathrm{Fe})$ treatment the SPAD values were high, between 48.3 for 'Leccino, and 63.1 for 'Manzanilla de Sevilla. In the (-Fe) treatment the SPAD values were lower for all the varieties, with values below 20 for five varieties and above 35 for three va-

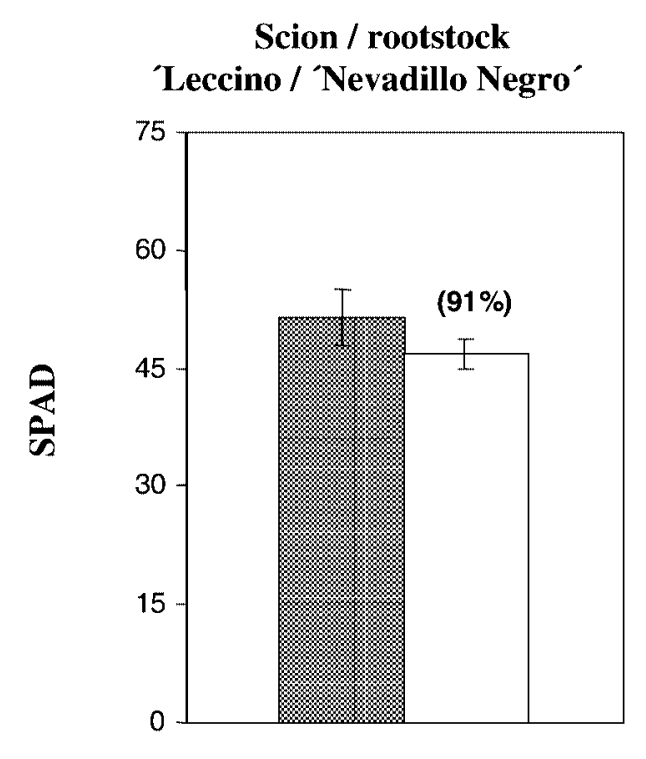

\section{Scion / rootstock 'Nevadillo Negro' / 'Leccino'}
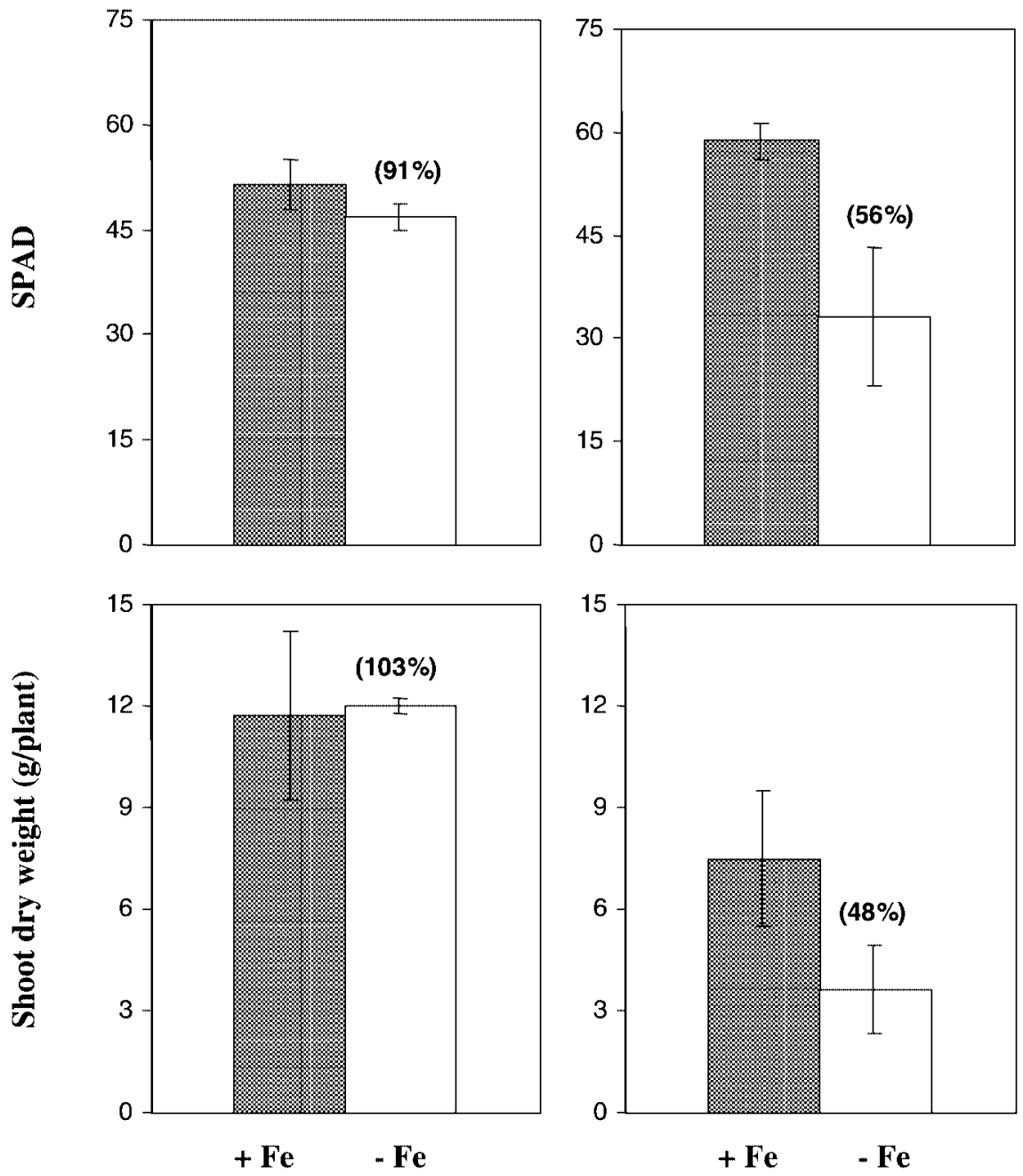

Figure 4. Final SPAD and shoot dry weight of the two reciprocal scion-rootstock combinations obtained with the olive varieties, <Leccino, and ‘Nevadillo Negro. Plants were grown in pots with calcareous soil fertilized with nutrient solution with $\mathrm{Fe}(+\mathrm{Fe})$ or without $\mathrm{Fe}(-\mathrm{Fe})$. Values are

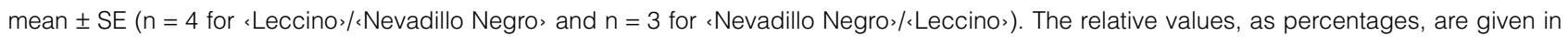
brackets. 
rieties. The shoot dry weight in the $(+\mathrm{Fe})$ treatment ranged from $6.2 \mathrm{~g}$ for ‘Galega> to $19.0 \mathrm{~g}$ for 'Lechín de Sevilla). In the $(-\mathrm{Fe})$ treatment growth was lower and again there were differences among varieties. Tolerance can be assessed by the relative chlorosis and growth in the $(-\mathrm{Fe})$ treatment with respect to the $(+\mathrm{Fe})$ treatment. These values, expressed as percentages, are shown in Table 1 and they are also represented as SPAD against shoot dry weight in Figure 1. Consequently, the varieties that were most susceptible were 'Leccino', ‘Arbequina', ‘Lechín de Sevilla〉 and 'Galega», most tolerant were ‘Nevadillo Negro', ‘Pajarero' and ‘Manzanilla de Sevilla', and intermediate was ‘Cornezuelo de Jaén.

In the second experiment, nine scion-rootstock combinations were compared. These were obtained by combining three varieties, ‘Hojiblanca〉, ‘Arbequina) and 'Lechín de Sevilla, used either as scion or as rootstock. Final SPAD and shoot dry weight are shown in Figures 2 and 3, respectively, with the ratios of the values of $(-\mathrm{Fe}) /(+\mathrm{Fe})$ expressed as percentages in brackets. Results show that tolerance was mainly determined by the variety used as rootstock. So, combinations with 'Hojiblanca) as rootstock were the most tolerant, followed by those with ‘Arbequina) as rootstock as intermediate and those with «Lechín de Sevilla as rootstock as most susceptible.

In the third experiment, the two reciprocal combinations between 'Leccino, and 'Nevadillo Negro, were compared. Results of final SPAD and shoot dry weight show again that tolerance was higher in the combinations that had the tolerant variety, ‘Nevadillo Negro`, as rootstock (Fig. 4).

\section{Discussion}

Olive trees are widely grown on calcareous soils of the Mediterranean area without showing, in general, problems of iron chlorosis. In consequence, this species is considered more tolerant than other fruit species such as peach or quince. Nonetheless, iron chlorosis has been observed in some olive orchards (Matar et al. 1977, Fernández-Escobar et al. 1993). This could be related to different causes such as: location specific poor soil or environmental conditions; use of irrigation, fertilization or higher plantation density, aimed to increase production; or the introduction of less tolerant varieties.

While genotypic differences in tolerance have been described for many species (Hamzé et al. 1986, Kolesch et al. 1987, Zaiter et al. 1988, Chaney et al. 1992, Tagliavini et al. 1993, Cianzio 1995, Socias i Company et al. 1995), the only information for olive trees comes from field observations, with the difficulties of interpretation that this involves. For this reason, the aim of this study was to evaluate the tolerance of several olive varieties under controlled conditions.

In previous investigations we tried the hydroponic method developed by the Chaney group (Coulombe et al. 1984) for herbaceous species. This method gave good results with peach rootstocks (Romera et al. 1991) but with olive there were several problems. Some varieties did not grow well in this system, fungal infections were frequent and in general the effects on chlorosis and growth were not well related. The growth in pots with calcareous soil is an alternative method used by others (Fairbanks et al. 1987, Ocumpaugh et al. 1992, Tagliavini et al. 1993, Wei et al. 1994) and as shown in the present study it has produced good results for olive. Wide differences in tolerance among olive varieties were identified based on the effects on chlorosis and growth that otherwise were well related. In the experiments with grafted plants it was also shown that tolerance was mainly determined by the rootstock genotype as occurs in other species (Byrne et al. 1989, Almaliotis et al. 1995, Socias i Company et al. 1995).

The results obtained in this study open the way to the use of olive varieties tolerant to those conditions in which iron chlorosis could become a problem. Nonetheless, it would be convenient to confirm the behaviour of the most tolerant varieties under field conditions.

Acknowledgements. This research was partially supported by the "Ministerio de Ciencia y Tecnología" (Proyecto AGL2000-1096) and by the "Junta de Andalucía» (Grupos AGR115 y AGR157). We thank the «Banco Mundial de Variedades de Olivo de Córdoba» for supplying plant material and we also wish to thank Ignacio Lorite for its collaboration in grafting the plants.

\section{References}

Almaliotis DD, Manganaris AG, Simonis AD, Bladenopoulou SB (1995) Rootstock effect on yield and mineral nutritin of "Maycrest" peach trees under conditions of lime-induced chlorosis. In: Abadía $J$ (ed) Iron Nutrition in Soils and Plants. Kluwer Academic Publishers, Dordrecht pp 301-306

Byrne DH (1988) Comparative growth of two peach seedling rootstocks under alkaline soil conditions. J Plant Nutr 11: 1663-1669

Byrne DH, Bacon T, Egilla JN (1989) Developing peach rootstocks for calcareous soils. Compact Fruit Tree 22: 87-89

Chaney RL (1984) Diagnostic practices to identify iron deficiency in higher plants. J Plant Nutr 7: 47-67

Chaney RL, Hamzé MH, Bell PF (1992) Screening chickpea for iron chlorosis resistance using bicarbonate in nutrient solution to simulate calcareous soils. J Plant Nutr 15: 2045-2062

Cianzio SR (1995) Strategies for the genetic improvement of Fe efficiency in plants. In: Abadía J (ed) Iron Nutrition in Soils and Plants. Kluwer Academic Publishers, Dordrecht pp 119-125

Cianzio SR, Fehr WR, Anderson IC (1979) Genotypic evaluation for iron deficiency chlorosis in soybeans by visual scores and chlorophyll concentration. Crop Sci 19: 644-646

Coulombe BA, Chaney RL, Wiebold WJ (1984) Use of bicarbonate in screening soybeans for resistance to iron chlorosis. J Plant Nutr 7: $411-425$

Fairbanks DJ, Orf JH, Inskeep WP, Bloom PR (1987) Evaluation of soybean genotypes for iron-deficiency chlorosis in potted calcareous soil. Crop Sci 27: 953-957 
Fernández-Escobar R, Barranco D, Benlloch M (1993) Overcoming iron chlorosis in olive and peach trees using a low-pressure trunk injection method. Hortsci 28: 192-194

Guerinot ML, Yi Y (1994) Iron: nutritious, noxious, and not readily available. Plant Physiol 104: 815-820

Hamzé M, Ryan J, Zaabout M (1986) Screening of citrus rootstocks for lime-induced chlorosis tolerance. J Plant Nutr 9: 459-469

Inskeep WP, Bloom PR (1986) Effects of moisture on soil pCO2, soil solution bicarbonate and iron chlorosis in soybeans. Soil Sci Soc Amer J 50: 946-952

Kolesch H, Oktay M, Höfner W, Schaller K (1987) Effect of bicarbonate and phosphate on iron chlorosis of grape-vines with special regard to the susceptibility of the rootstocks. I. Field experiments. J Plant Nutr 10: 207-230

Korcak RF (1987) Iron chlorosis. Hort Rev 9: 133-186

Lindsay WL, Schwab AP (1982) The chemistry of iron in soils and its availability to plants. J Plant Nutr 7: 821-840

Loeppert RH (1986) Reactions of iron and carbonates in calcareous soils. J Plant Nutr 9: 195-215

Matar AE, Petros M, Naddaf AM, Nseir P (1977) Diagnosis and control of lime-induced chlorosis on olive trees grown under dry farming conditions by iron chelates. Olea 6: 7-30

Ocumpaugh WR, Rahmes JN, Bryn DF, Wei LC (1992) Field and greenhouse screening of oat seedlings for iron-nutrition efficiency. J Plant Nutr 15: 1715-1725
Perret P, Koblet W (1984) Soil compactation induced iron-chlorosis in grape vineyards: Presumed involvement of exogenous ethylene. J Plant Nutr 7: 533-539

Romera FJ, Alcántara E, de la Guardia MD (1991) Characterization of tolerance to iron chlorosis in different peach rootstocks grown in nutrient solution. I. Effect of bicarbonate and phosphate. Plant and Soil 130: 115-119

Römheld V, Marschner H (1986) Mobilization of iron in the rhizosphere of different plant species. Adv Plant Nutr 2: 155-204

Shi Y, Byrne DH (1995) Tolerance of prunus rootstocks to potassium carbonate-induced chlorosis. J Amer Soc Hort Sci 120: 283-285

Singh RA, Sinha NP, Singh BP, Sharma SG (1986) Reaction of chickpea genotypes to iron deficiency in a calcareous soil. J Plant Nutr 9: $417-422$

Socias i Company R, Gomez Aparisi J, Felipe AJ (1995) A genetical approach to iron chlorosis in deciduous fruit trees. In: Abadía J (ed) Iron Nutrition in Soils and Plants. Kluwer Academic Publishers, Dordrecht pp 167-174

Tagliavini M, Bassi D, Marangoni B (1993) Growth and mineral nutrition of pear rootstocks in lime soils. Sci Horticult 54: 13-22

Wei LC, Ocumpaugh WR, Loeppert RH (1994) Differential effect of soil-temperature on iron-deficiency chlorosis in susceptible and resistant subclovers. Crop Sci 34: 715-721

Zaiter HJ, Coyne DP, Clark RB (1988) Genetic variation, heritability, and selection response to iron deficiency chlorosis in dry beans. $J$ Plant Nutr 11: 739-746 